\title{
LOS CUENTOS MOTORES COMO HERRAMIENTA PEDAGÓGICA PARA LA EDUCACIÓN INFANTIL Y PRIMARIA
}

\author{
Julia Iglesia \\ Diplomada en Magisterio Educación Infantil y Educación Física. Centro de Enseñanza \\ Superior Cardenal Spínola.
}

\section{Resumen}

Hoy día, la sociedad plural y cambiante hace que hayan evolucionado valores que antes eran fundamentales. Como comenta Esteve (1995: 280) "frente a la mentalidad contemporánea del filiteísmo, que sólo valora vivir a lo grande, los profesores necesitamos recuperar el sentido de la grandeza oculto en la sabiduría”.

Priorizamos objetivos y valores que ahora son "más importantes" por otros que lo son menos. Modificamos muchos aspectos en la enseñanza pero la forma, el modo de conseguirlo puede ser la de siempre, la tradicional que ha dado resultados positivos.

A través de juegos y cuentos motores alcanzamos dichos fines. Juegos de siempre o que nuestras generaciones han practicado. Juegos que huyen de máquinas externas, de juegos digitales, de videojuegos... y que a través de simulaciones y dramatizaciones consiguen los efectos deseados.

El cuento refuerza la capacidad de imaginar. Cuando se está escuchando un cuento, el niño/a desarrolla una condición protagonista al hacer de intérprete e intermediario y receptor. El binomio 
que se crea entre la persona que cuenta el cuento y el que la escucha provoca un lazo de afectividad que es la primera pieza clave de la socialización del niño/a.

Esta condición de protagonista en el cuento escenificado o cuento motor se multiplica, ya que al niño/a se le integra plenamente en lo que se está contando y se hace protagonista activo al ir representado lo que en él se cuenta, provocando, por otro lado, que estos lazos afectivos que hemos venido refiriendo también se multipliquen.

\title{
Palabras clave
}

\section{Cuento escenificado o motor - Socialización -Simulación - Juego}

\section{Abstract}

Today the plural and changing society causes that values have evolved that before were fundamental. As Esteve (1995: 280) comments, about the mentality contemporary of filiteism, that has it values to live to the great thing, the professors we needed to recover the sense of the hidden greatness in knowledge. We prioritized objectives and values that now are important. We modified many aspects in learning but the form, the way to obtain it can be the one of always, the traditional one that has given positive results. To motor games and stories we reached these aims. Old games or that our generations have practiced. Games that flee from external machines, digital games, videogames... and that to simulations and theatrical forms obtain the wished effects. The story reinforces the capacity to imagine. When child hears a story, boys and girls develop a condition of story star, when doing of actor and intermediary and receiver. The binomial, that is created between the person whom the story tells and the one that listening, causes affectivity bow that is the first key piece of socialization of children.

\section{Keywords}

\author{
Staged story - Socialization - Simulation - Game
}




\section{Introducción}

Los cuentos motores son cuentos que, al ser narrados y con la ayuda de la música, propician una amplitud interesante de movimientos, juegos, simulaciones y dramatizaciones.

Nos pueden servir como herramienta pedagógica para que nuestros alumnos/as exploren sus múltiples posibilidades motrices y creativas y/o puedan vivenciar diversas situaciones, ya sean de forma sugerida o libre y espontánea.

\section{Metodología}

Siguiendo las técnicas que utilizan el teatro o la dramatización como medio terapéutico de diversas dolencias mentales, emocionales o físicas, emprenderemos una reflexión sobre el uso del cuento motor en la enseñanza al tiempo que se ejemplificará con casos prácticos concretos puestos en práctica en diversos colegios de las provincias de Córdoba, Cádiz y Huelva durante el año académico 2006/2008. La metodología seguida en estas prácticas con alumnos de infantil y primaria han sido las de Conde sobre el cuento motor y de Koldovika sobre el match de improvisación.

\section{Los cuentos motores en la educación}

Un cuento motor podemos definirlo como un cuento jugado, un cuento vivenciado de manera colectiva, con unas características y unos objetivos propios (Conde, 2001). Siguiendo a este mismo autor, de entre sus innumerables características podemos destacar las siguientes:

- $\quad$ El cuento motor es un eslabón previo al cuento escrito, y puede ir paralelo al cuento narrado. 
- $\quad$ El cuento motor incide directamente en la capacidad expresiva de los niños/as (primero se interpreta cognitivamente y luego se interpreta motrizmente).

- $\quad$ El niño/ a, cuando ejecuta el cuento motor, se convierte en protagonista absoluto.

- $\quad$ El cuento motor es una fuente motivadora que despierta en los niños/ as el interés por descubrir historias y personajes, y les ayuda a introducirse en los caminos sorprendentes de los libros, del teatro y compara con otras formas de entretenimiento menos participativas.

Los objetivos que pretenden desarrollar los cuentos motores son, según Conde (2001):

- Hacer al niño/ a protagonista, desarrollando su conducta cognitiva, afectiva, social y motora.

- Desarrollar los elementos psicomotores básicos (esquema corporal, lateralidad, estructuración espacial y temporal y ritmo), las cualidades motrices coordinativas (coordinación y equilibrio), las habilidades básicas (desplazamientos, saltos, lanzamientos, recepciones y giros), las habilidades genéricas (bote, conducciones, golpeos, etc.)...(Junta de Andalucía, 1992c).

- Desarrollar las capacidades físicas básicas de manera indirecta.

- Sentar las bases preventivas e higiénicas de la salud a través del ejercicio físico desde las primeras edades y como un hábito de vida que irá marcando lo que serán sus futuras costumbres.

- Desarrollar la capacidad creativa del niño/a, haciéndole interpretar corporalmente lo que se le está verbalizando, potenciando el desarrollo de su imaginación y construyendo sus capacidades cognitivas.

- Globalizar la enseñanza de las áreas musical, plástica y dramatización y lengua, entre otras, partiendo del centro de interés: el cuento infantil.

Descubrir el propio cuerpo como vehículo de comunicación.

Enfrentar al alumno/a a la toma de sus propias decisiones en cuanto a expresión y movimiento, tomando conciencia de su cuerpo y del espacio que le rodea.

- Interdisciplinar otras áreas, principalmente Música y Plástica, con el fín de globalizar la enseñanza. 
Sin duda, todas estas características y objetivos del cuento motor, acercan al niño a través de la simulación de la dramatización a una experiencia diferente a la simulación que realizan de sí mismos en el entorno cibernético, donde la interpretación se reduce a crear un yo paralelo, distinto de un yo desaparecido en la interpretación actoral del cuento motor.

Con respecto a los requisitos necesarios la hora de transmitir el cuento, debemos tener en cuenta innumerables factores tanto antes de contar el cuento como durante la transmisión del mismo. Por ello nombramos las siguientes consignas (Martínez, 2007):

- La persona responsable de la actividad ha de conocer muy bien el cuento, con el fin de mantener una dinámica flexible pero sin perder de vista los objetivos.

- Disponer a priori del material que se vaya a utilizar y preparar su ubicación y utilidad.

- Disponer de un espacio amplio y/o abierto (gimnasio, patio, campo...).

- Integrarse como uno más en la práctica de la actividad.

- La sesión deberá seguir una estructura dividida en tres partes (fase de animación, fase principal o de desarrollo de la actividad, y vuelta a la calma).

- Una vez finalizada la sesión, podemos mantener una charla con los niños/ as (dispuestos en corro) y trabajar así otros contenidos más relacionados con la compresión y expresión orales.

Esta actividad es generadora de otras muchas (dibujos, plastilina, canciones...) que podemos aprovechar según intereses y circunstancias.

En cuanto al argumento del texto, éste debe posibilitar la estimulación habitual de una sesión de Educación Física. Su duración, es conveniente, debe estar comprendida en una misma sesión, que se inicie y termine en una misma clase. El maestro/ a, en principio, es el conductor/ animador del cuento. Cuando éste crea conveniente hará que los niños/ as participen en la creación del cuento. También debemos establecer un sistema de señales alternativo para usarlo cuando por la música o el alboroto la voz no se oiga. 
En cuanto a las consignas que debe seguir el maestro/ a destacamos las siguientes:

a) El narrador/a debe conocer el cuento antes de contarlo.

b) El narrador/a debe saber que en el texto aparecen el cuento y las acciones sugeridas.

c) Lo que va entre paréntesis o en una columna diferente es la acción sugerida, aunque puede ser conveniente decirlo para introducir a los niños/as en situación (ver ejemplos propuestos).

\subsection{Desarrollo del cuento motor}

Comenzamos con la narración del cuento y cuando aparezca un número o pausa ponemos la música. El narrador/a se detiene en el acto de contar el cuento y los niños/as realizan el ejercicio indicado, durante el tiempo que estime oportuno el narrador/a.

Cuando el narrador/a para la música los niños/as deben permanecer inmóviles y la acción continuará cuado vuelva a sonar la música. Así hasta que finalice el cuento. La música debe ser apropiada al tema del cuento y es aconsejable la música instrumental.

En definitiva, es conveniente conocer el relato y vivenciarlo, crear un ambiente favorable de aprendizaje, realizar una elocución sencilla, prever los materiales necesarios, entre otros.

Debemos tener en cuenta los diferentes tipos de cuentos que existen: cuentos cerrados o dirigidos y cuentos abiertos o autónomos. En ambos casos, los cuentos deben ser inventados por el narrador/a y los niños/as, deben ser cuentos populares adaptados o cuentos mitológicos.

En cuanto a la metodología práctica debemos tener en cuenta los siguientes aspectos (Martínez, 2007):

- Establecimiento de períodos de quietud y movimiento.

- Participación continua y activa de los niños/as.

- Se aplica esquema de una sesión habitual de Educación Física. 
- Será más autónoma según el desarrollo o las edades de los discentes.

- Recomendable es, como hemos sugerido antes, una asamblea al finalizar la sesión.

\subsection{Casos prácticos de cuentos motores}

A continuación mostramos diferentes ejemplos que podríamos usar en nuestras sesiones de clase, tanto con alumnos/as de Educación Infantil como de Primaria.

\section{TÍTULO: UN VIAJE A LA LUNA}

\section{Descripción}

Había una vez un grupo de niños/as que quería viajar a la luna, pero por mucho que lo intentaban no sabían cómo llegar hasta ella.

Un día, paseando por el bosque, se encontraron con un sapo de ojos saltones que les dijo que para alcanzar la luna debían imitarle.

Como no conseguían nada, se le ocurrió una idea al sapo:

- ¿Y por qué no, croac, saltamos lo más alto que podamos y nos estiramos a la vez para ver si así, croac, llegamos?

Todos los niños/as comenzaron a saltar intentando llegar hasta

\section{Actividad motriz}

$\underline{\text { Habilidad motriz }}$

Desplazamiento libremente por todo el espacio (gimnasio).

\section{Desplazamie}

\section{ntos}

Se distribuyen por parejas, imitando uno al otro $y$ viceversa.

Esquema corporal.

Saltan de diferentes formas de forma individual.
Desplazamientos.

Espacialidad. 
la luna, pero continuaban sin poder.

Los niños/as siguieron paseando por el bosque un poco desilusionados hasta que vieron un gran árbol y decidieron escalarlo.

Cuando el árbol notó a los niños/as en sus ramas les preguntó qué era lo que pretendían y les dijo que el gran pájaro rojo, que había posado en una roca, conocía el camino para llegar hasta la luna y que les llevaría.

Así, que se pusieron en camino siguiendo las instrucciones del gran pájaro:

-Primero, debéis pasar por este sendero, pero es muy estrecho y tenéis que caminar con un pie delante de otro y de puntillas, de tal manera que tenéis que llevar mucho cuidado para no tropezar.

- Ya hemos llegado a la explanada de hoyos. Tenéis que pasar esquivándolos para no caeros dentro.- les seguía explicando el gran pájaro.

- Humm, ahora encontramos dos caminos ipero no recuerdo que camino debéis coger!- gritó el pájaro.

Bueno, ¿veis las dos rocas grandes que hay al principio de cada camino?- les preguntó el pájaro.

- Pues... debéis probarlas y seguir el camino de la roca dulce.- les dijo.

- ¿Pero cómo vamos a probar una roca? Gritaron los niños/as. - No os preocupéis, son
Trepan por las espalderas.

\section{Desplazamientos.}

Espacialidad.

Se desplazan por las líneas del suelo de puntillas y caminando con un pie delante de otro.

Equilibrios.

Se desplazan a saltitos con los pies juntos esquivando los aritos en zig-zag.

Equilibrios. Desplazamientos.

Se colocan en fila y van probando una pizquita de sal y otra de azúcar,

Esquema corporal. identificando el sabor dulce. 
comestibles.- les tranquilizó el gran pájaro.

- Ahora debéis seguir el camino vosotros solos. Al final, encontraréis una gruta que tendréis que explorar.- les dijo el pájaro mientras se alejaba volando.

- ¡Qué tengáis mucha suerte!exclamó el pájaro.

Atravesaron el camino y llegaron a la gruta. Cuando entraron estaba todo oscuro y tuvieron que hacerlo sorteando los obstáculos que encontraban a través del tacto.

Al salir de la gruta encontraron a un ciervo que les dijo que para seguir el camino, debían coger una piedra cada uno y mantenerla en la mano mientras escuchaban el canto de los pájaros, cuando éste parara la tenían que lanzar hasta llegar a las piedras que conducían a la cueva.

Cuando llegaron a la cueva se preguntaron: - ¿Y ahora qué hacemos?

- Debéis formar un corro y cantar una canción a la vez que vais girando, primero hacia un lado y después hacia el otro.- les dijo una margarita.

De repente, justo cuando los niños/as terminaron de cantar, se puso a llover y se tuvieron que esconder en la cueva.

- ¡Oh, no! ¡Ahora que casi lo habíamos conseguido! ¡Con el buen día que hacía!- Exclamaron los niños/as.
Por parejas, de frente, cogidos de los hombros unos al lado de otros formando una gruta. Uno a uno va pasando con los ojos vendados.

Espacialidad.

Desplazamiento.

Esquema corporal.

\section{Manipulaciones.} Temporalidad.

para la lanzan a un compañero/a.

Los niños/as juegan al corro, girando hacia ambos lados.

Espacialidad.

Caminan libremente y al dar una palmada, buscan "refugio" (encima de cualquier material: bancos suecos, espalderas,...).
Espacialidad.

Desplazamientos. 
Y con la misma rapidez con la que se había puesto a llover, paró.

Entonces, salió el Arco Iris. Al verlo, los niños/as lo comprendieron todo. Se cogieron de la mano y en parejas fueron subiendo por el arco iris hasta el cielo.

Allí, encontrarían a la luna.

Una vez en el cielo, buscaron hasta encontrar a la luna que se encontraba dormida.

Los niños/as estaban tan cansados que decidieron acostarse junto a ella en las cómodas nubes.

Y colorín, colorado junto a la luna descansaron.
Se tumban en el suelo, estirando y relajando todo el cuerpo.

\section{Esquema Corporal}

\section{TÍTULO: PAPÁ, QUEREMOS IR AL CIRCO.}

\section{Descripción}

Nuestros alumnos/as, están muy inquietos e impacientes porque ha llegado el día que tanto tiempo habían estado esperando, sus padres los van a llevar al circo. Están muy nerviosos porque se han despertado tarde y tienen que recoger su cuarto para irse.

\section{Actividad motriz}

Habilidad motriz

Los niños/as corren de un lado a otro del gimnasio.
Desplazamientos. 
Primero van rápidamente a la cocina y desayunan, pero eso sí, más tranquilamente, porque no es bueno desayunar rápido.

Luego vuelven a su cuarto y lo ordenan ¿cómo? Primero hacen sus camas: ¿cómo la hacéis vosotros, a ver?.

Una vez echas las camas, se agachan para recoger los enredos del suelo, mirando si hay algo debajo de las camas.

Una vez recogido el cuarto van al aseo y allí:

Se lavan los dientes, la cara, se peinan y se visten: los pantalones ¿dónde? ¡En las piernas! Los zapatos, ¿dónde? ¡En los pies! La camiseta, ¿dónde? ¡En el tronco! ¿La bufanda? ¡En el cuello! ¿Los guantes? ¡En las manos! Y... ¿el gorro? ¡En la cabeza!

Ya salen por la puerta, empiezan a andar $\mathrm{y} . .$.

...j llegan al circo!. ¡Ohhh! ¡El circo es gigante!. Hay de todo: payasos, fieras, bailarinas, malabaristas...

Antes de ver el espectáculo vamos a ver las jaulas de los animales y nos paseamos por el circo en busca de ellos.

De repente oyen un rugido ¡GRRRR!, ¿Qué será?.¡Un león!. Sus dientes estaban muy afilados y su cuerpo lleno de pelos y... ¿cómo andan los leones?

Los niños/as siguen caminando y ahora... oyen unos gritos: ¡HI, HI, HI!, ¿Qué será?- se preguntaban los niños/as. ¡Son monos! Su cola
Se divide el gimnasio en cuatro partes: el cuarto de los niños/as, la cocina, el aseo y la puerta de entrada.

\section{Los niños/as deben} desplazarse al rincón correspondiente cuando se nombre e imitar las acciones que corresponden.

\section{Los niños/as continúan} imitando el papel de correspondiente señalando y diciendo la parte del cuerpo correspondiente en él y tocando las partes nombradas en el cuerpo de sus compañeros/as.

Caminan hacia la zona de la puerta.

Esquema corporal. Desplazamientos.
Desplazamientos.

Desplazamientos. Temporalidad. Espacialidad.

Esquema corporal.
Se les pone una música con los sonidos de los animales y los niños/as tienen que adivinarlos e imitarlos. 
era larga y se colgaban en los árboles. ¿Sabéis cómo andan los monos?.

Los niños/as continúan escuchando otros sonidos, pero estos no provienen de ninguna jaula sino de la charca ¡CROAC, CROAC! ¿Qué podrán ser? ¡Ranas! Y, ¿cómo se desplazan las ranas?.

De repente... ¿qué pasa? El suelo empieza a moverse a la vez que se oye un enorme ruido cada vez más próximo. Levantan la vista viendo como un montón de elefantes se dirigen hacia donde ellos están.

Detrás, vienen payasos, malabaristas... Y, sin pensarlo dos veces, se apartan de su camino. ¡Todos a la derecha! ¡Todos a la izquierda! ¡Hacia abajo que los monos saltan!

Ufff!. ¡Cuánta tensión!. Después de tanto correr les ha entrado un hambre terrible, así que van a una tienda a comer algo. Hay muchos bocadillos diferentes, pero también hay un problema: se ha fundido la

luz de la tienda y tienen que descubrir, por el sabor, el bocadillo que quieren.

¡Jo!, ¡Qué pena! También tienen que hacer lo mismo con las bebidas, pero estas tendrán que averiguarlas por el olor.

Por fin, hemos comido, y nos reunimos con nuestros padres para ver el gran espectáculo. Todo el mundo espera sentado impaciente en círculo. El Payaso Mikito, jefe del circo, saluda a todos los niños/as y les pregunta: ¿os gusta el circo? ¿Y los payasos?¿Sí? Seguidamente salen los demás payasos jugando a
Todos corren como si

fueran los protagonistas, $\mathrm{y}$ de diferentes formas: agachados, de cuclillas, arrastrándose...

Se tapan los ojos con un pañuelo y van probando trozos de bocadillos rellenos de diferentes condimentos identificando de qué son por el sabor. Al final se les da un trozo más grande del que más les guste.

Se tapan los ojos y deben oler vasos que el maestro/a pondrá con distintas bebidas:, refresco, zumo, agua... y averiguar qué es cada cosa.

Los niños/as, en parejas, cogen un balón y siguen las instrucciones del maestro/a haciendo que son los payasos. Luego, juegan a ser conductores y cogen un aro por pareja, uno se mete dentro del aro poniéndoselo a la altura de la cintura y
Desplazamientos. Espacialidad.

Esquema corporal.

Esquema corporal.

Desplazamientos.

Espacialidad.

Manipulaciones. 
los bomberos pasándose entre ellos

y los espectadores un balón

imitando que quema mucho. Y

ahora, ¿qué hacen? Van caminando y se lo siguen pasando primero con las manos y luego con el pie porque juegan a ser futbolistas. ¡Anda, son conductores! Ahora se mueven por toda la pista ¡curva a la derecha, curva a la izquierda! Dando saltitos porque hay baches...

¡BIEEEN!. Ya acabaron los payasos y ahora vienen las bailarinas ¡Mirad, están danzando de puntillas!

Toda la gente observaba encantada. A continuación: ¡los equilibristas!. Estos salen y empiezan a andar por la cuerda floja con un balón en las palmas de las manos.

Y por último... ¡los leones! Cada león tiene su domador que sujeta un aro de fuego y los leones lo saltan de atrás a delante y al revés; después, hacen una fila todos los domadores formando un túnel de aros por el que salen y entran los leones. Continúa cada león saltando por el aro de su domador de más abajo a más arriba. otro lo dirige por atrás siguiendo las instrucciones del maestro/a.

Se desplazan de puntillas, saltando y girando.

Equilibrios.

Desplazamientos.

Saltos.

Giros.

Equilibrios.

Desplazamientos.

Después se desplazan por la línea arrastrándose, como los malabaristas.

Se ponen por parejas: uno hace de domador y otro de león. Un niño/a coge un aro y el otro lo pasa por su interior a diferentes alturas. Espacialidad. Manipulaciones. 
Con este espectacular acto acaba el espectáculo. Volvemos a casa donde tranquilamente y muy cansados nos metemos en la cama relajándonos, pensando en todas las cosas bonitas y divertidas que hemos visto hoy en el circo y pensando que ha sido uno de los mejores días de nuestra vida.
Con música relajante se desplazan lentamente por toda el espacio, y continúan Desplazamientos. Esquema corporal. relajados en el suelo.

\section{Conclusiones}

- En Educación Infantil se puede trabajar "bien” Educación Física sin volverse "loco" con la ayuda de la dramatización natural no maquinizada.

- Las sesiones son vivas, son cuerpos en movimiento.

- Resulta muy fructífera la interdisciplinariedad y transversalidad del cuento y de la actividad física.

- Con el empleo de los cuentos motores se produce un incremento del tiempo útil, sobre todo en edades más tempranas y ayudan al niño/a a encontrar otras formas de ocio y cultura distintas de las derivadas de las nuevas tecnologías.

\section{Bibliografía}

[D] BOAL, Augusto (2004): El arcoiris del deseo: Del teatro experimental a la terapia, Barcelona, Alba Editorial.

[D] CONDE CAVEDA, J. L. (2001): Cuentos motores, Barcelona, Paidotribo.

[D ESTEVE, J. M.; S. FRANCO y J. VERA (1995): Los profesores ante el cambio social, Barcelona, Anthropos.

[D] MACER, Á. (2004): Taller de teatro. Cómo organizar un taller y una representación teatral, Barcelona, Alba Editorial.

[DQ MARTÍNEZ CALLE, A. (2007): Cuentos motores, Sevilla, Wanceulen. 
[Qd JUNTA DE ANDALUCÍA (1992a): Decreto 107/92 de 9 de Junio de 1992 por el que se establecen las Enseñanzas correspondientes a la Educación Infantil en Andalucía.

[Dd JUNTA DE ANDALUCÍA (1992b): Decreto 105/92 de 9 de Junio de 1992 por el que se establecen las Enseñanzas correspondientes a la Educación Primaria de Andalucía. Anexo I y II.

[D JUNTA DE ANDALUCÍA (1992c): Orden de 5 de Noviembre de 1992, por la que se establecen criterios y orientaciones para la elaboración de Proyectos curriculares de Centro, secuenciación de contenidos y distribución horaria en Educación Primaria.

[D KOLDOVIKA, V. (1998): Explorando el match de improvisación: Propuestas para su entrenamiento y su utilización pedagógica, Madrid, Ñaque Editora.

[D] VVAA (2004): Cuentos motores, CD. En línea http://www.um.es/univefd/producciones.htm $(13 / \mathrm{III} / 2008)$. 